\title{
Producciones culturales en la Argentina contemporánea. Experiencia y sensibilidad
}

\author{
Nancy Fernández*
}

\section{Resumen:}

El trabajo intenta pensar las producciones culturales y artísticas argentinas de la actualidad, teniendo en cuenta a los escritores y críticos Alan Pauls, Sergio Chejfec y Daniel Link. La categoría de síntoma (Freud; Sloterdijk) será una clave para analizar el sentido de la experiencia, de la historia, de lo real, de las estrategias identitarias, del espacio urbano y territorial, de la actual dinámica social y del lugar que la misma producción cultural está demandando, en relación a sus propias condiciones de posibilidad y sus vínculos con nuevos circuitos de legitimación.

\section{Palabras clave:}

Producción cultural; experiencia; imagen; intimidad; comunidad

En el presente trabajo intentaremos pensar las producciones culturales y artísticas argentinas de la actualidad. Para ello tendremos en cuenta como punto de inflexión a los escritores y críticos Alan Pauls, Sergio Chejfec y Daniel Link, los tres pertenecientes (en distinta medida) al grupo Babel de la década de los noventa. Más allá de tener en cuenta las figuras que dicha línea recuperaba, procuraremos abordar esa proyección hacia el presente, en tanto campo cultural e intelectual en plena formación; las supuestas divisorias y poéticas que nuevos escritores están haciendo visibles. En este sentido la categoría de síntoma (Freud; Sloterdijk) será una clave para analizar el sentido de la experiencia, de la historia, de lo real, de las estrategias identitarias, del espacio urbano y territorial, de la actual dinámica social y del lugar que la misma producción cultural está demandando, en relación a sus propias condiciones de posibilidad y sus vínculos con nuevos circuitos de legitimación. Sin duda tanto en Pauls como en Chejfec hay una idea de literatura que subyace a sus poéticas. Operaciones de distanciamiento y estetización que se vinculan con filiaciones y préstamos pero también con el tiempo que marca el diálogo, el tributo o la parodia. Acá el proceso supone dialéctica y mediación, una necesaria toma de distancia donde las referencias culturales se constituyen como materia prima. Pensando en Wasabi y en El pasado, Pauls repone a Hugo, Shakespeare, Klossowski; a Proust, a Dante. Mientras, en Chejfec son legibles marcas

\footnotetext{
* Una versión de este trabajo fue leído en las Jornadas "Experiencia, cuerpo y subjetividades: Literatura brasileña y argentina del presente". El evento fue organizado por Florencia Garramuño, Gonzalo Aguilar, Mario Cámara, Luciana Tennina y Lucía Di Leone, en la Universidad de San Andrés, Buenos Aires, Argentina, 20 y 21 de agosto del 2009.

** Docente especializada en literatura argentina de la Universidad Nacional de Mar del Plata e investigadora del CONICET.
} 
de Schowb, de Martínez Estrada, de Aira, Saer y en importante medida Sebald. Ambos son autores que experimentan con la tradición: si Pauls con frecuencia estiliza géneros y tópicos clásicos, Chejfec elabora un tono impasible, neutral que le permite adoptar una perspectiva objetiva desde donde instala la base de su experiencia, que a veces es ficción autobiográfica (Lenta biografía, Los planetas, Baroni, Mis dos mundos). Inclusive ambos desmitifican nociones que tienen peso en la historia de la cultura occidental, como la que concierne a la profundidad de los grandes relatos, relectura que también viene de Saer, Piglia y Aira. Asimismo, sus personajes están construídos sobre fisonomías distanciadas y ajenas, algunas veces, como en el caso de Pauls, se trata de poner en otro contexto antiguos motivos pasionales, vinculados al voyeurismo (El pudor del pornógrafo) y las misivas, y en Chejfec el uso de las cartas como un motivo más, la tradición cabalística, la historia política nacional con nombres que aparecen desaprendidos en iniciales o en apellidos. Como sea, en ambos hay una fuga, un devenir, deambulación que altera no solo el ritmo lineal de la escritura sino las figuraciones, escenas y mundos que aparecen al comienzo y mutan el sentido y su lógica, volviendo a los finales imprevistos y contingentes. El cálculo hiperbólico de distancias y magnitudes (que se daba en El aire de Chejfec y retorna en Wasabi y El pasado de Pauls) Si miramos hacia atrás, Saer, Piglia y Aira son puntos de anclaje, escritores donde la idea de literatura (más compartida por Pauls y por Chejfec) implica el resultado de una práctica secularizada y sostenida en un trabajo guiado por sus propias reglas. Lenguaje, alegoría o ready made, aquí persiste una idea de narración artística, si no en términos de especificidad, sí en lo relativo a una forma propia, un estilo y de alguna manera, cierta idea de obra más allá del texto. De alguna manera, tiene vigencia incluso, el concepto de valor, el gusto y la calidad aunque desplacen el lugar del museo. Se trata ni más ni menos de la potencialidad experimental que alterna con el canon, con el modelo de la alta literatura sacralizada.

En un reciente trabajo intenté marcar a grandes rasgos al menos dos líneas donde reconocía afinidades electivas entre Martín Kohan, Damián Tabarovski y Carlos Gamerro (más los nombres de Martín Rejtman, Eduardo Muslip y Pedro Mairal por mencionar otros, aportan sus hallazgos en lo que hace a los realismos urbanos). El nombre de Sergio Bizzio también suena como referente sobre todo pensando en dos de sus novelas, Infierno albino y Rabia). Sin embargo, en algunos de los autores más recientes sobre los que pasaremos revista, la distancia de la deuda parece quedar saldada o diluída.

Pero es a partir de Daniel Link donde prefiero indagar un campo de acción más nuevo. Link, no como causa inequívoca y suficiente sino quizá, como enlace, como aquel tipo de precursor kafkiano que supo entrever Borges al invertir la noción de influencia y determinación. Por impacto y recepción, es sin duda uno de los referentes de la cultura contemporánea. Doble operación que negocia con los modelos canónicos y con las estéticas emergentes y medios masivos, que entablan su affaire con el margen, no por depender de la aceptación general, sino más bien ser producciones fronterizas, bordes en el lenguaje de la cultura. Creo que se trata de ver en los blogs, género y práctica que Link anticipa, cierta revitalización de 
viejos registros cuyas normas y valores (en perspectiva de Mukarovski) cambian de sentido. Diario íntimo, cuaderno de bitácora, de apuntes o de viajes, autobiografías fragmentarias. Se trata entonces, de mirar con ellos una "literatura" que siempre fue y será política en el sentido de recortar subjetividades ligadas a una cultura y a una época.

Llegados los noventa y además de Babel, se suscitan otros cambios respecto del modo de leer el pasado libresco y es la poesía uno de los factores que llama la atención, en gran medida y por efecto retrospectivo, gracias al impacto que generó la antología Monstruos, de Arturo Carrera, realizada en 2001. Allí aparecerán algunos nombres que darán forma al sentido literal del título, en tanto fenómeno que aparece para mostrar, esto es, provocar exhibiendo si no rareza o anomalía, sí la transformación del vínculo entre ancestros y pares. Monstruos pone en escena el prodigio del acontecimiento de la visibilidad; así, lo visual impregna una grieta, allí donde comienza a asomar un rastro emergente, fecundo en su despojo: la pobreza. La imagen será entonces, uno de los aspectos primordiales de la creación hacia finales del siglo XX y la obscenidad su lado oscuro y latente. En esta línea, lo obsceno en su acepción siniestra, resulta operativo en tanto pulsión de lo visible. Carrera hacía sonar así, la nueva "campana de palo" que, lejos de anular procedencias, entre ellas, la remisión a la vanguardia histórica y al grupo de Boedo, más bien señala la novedad con que los jóvenes artistas hacen uso de su herencia; elogio de la simpleza, donde la vanguardia de los años veinte con Oliverio Girondo, la neovanguardia de los setenta con Osvaldo Lamborghini, Ricardo Zelarayán, más el lugar que va ocupando Leónidas Lamborghini desde mediados de los cincuenta, constituye el acervo de un tributo naturalizado, sin parodia ni exaltación. En esto se diferencian del culto a lo nuevo y la ruptura estridente con que la vanguardia hacía su entrada inaugural en la década del veinte, cuando la parodia supone la relación especular con otro texto. No unicamente en la perspectiva del Formalismo Ruso, sino en el sentido genuinamente historicista: la memoria libresca dota de sentido al mundo. Ahora, el pasado, (los textos y la política), entra en sintonía con la contemporaneidad sin solemnidad aunque de a poco esos mismos años menemistas vayan borrando las huellas de la historia. Como en un campo minado, los nuevos artistas procuran reconstruir el mapa de la cultura, a partir de los escombros; por un lado, hacer visible es una de las claves de los nuevos trabajos, por otro, esa misma "pobreza" será el material que señala el despojo en tanto modo de leer hacia atrás y hacia adelante. Reordenar el patrimonio recibido implica cierto "malestar de la cultura" en el momento de barajar y dar de nuevo, tratando de adaptarse a su vez a la globalización de la economía y a la juridicidad de los nuevos artífices del capitalismo, esto es, las condiciones y la falta de fronteras en la transacción empresarial (ver Bauman). Diríase que no hay firmas ni rastros en el flujo actual del mercado y sus servicios. Tampoco hay huellas ni responsabilidad institucional ni marcos estables en los negocios actuales.

Entre el gesto consciente y desenfadado por leer a los congéneres y cierta levedad a la hora de filtrar la autoridad de los legados, la historia (la política y la cultu- 
ral), ingresa fragmentada en las escrituras argentinas de hoy. Martín Gambarotta (Punctum, Seudo), Sergio Raimondi (Poesía civil), Alejandro Rubio (Música mala, Metal pesado), Martín Rodriguez (Agua negra) Emiliano Bustos (Poema a la intemperie, Cheetah), Washington Cucurto y Fabián Casas, estos últimos alternando entre las convenciones genéricas de prosa y poesía (en tanto son reconocidos como poetas y narradores) y algunos otros, toman en préstamo las notas de un sistema de filiación, con reconocimiento y a veces como homenaje (por ejemplo Cucurto y Zelarayán), pero nunca con la respuesta a una exigencia de devolución. Así, los textos adoptan el gesto de quien toma sin culpa ni cargo lo que no se considera ajeno. Desde esta perspectiva, hay consciencia de los pactos y convenios, una mezcla de respeto y a su vez, un gesto de proximidad, advertencia de las heredades que constituyen los nombres propios, los circuitos de legitimación y las entidades que financian y otorgan prestigio (fundaciones, concursos, centros culturales, etc.) Pero lo que queda de la última dictadura y de la década de los noventa, es la memoria, si no vacía, traumada, indolente y discontinua. En este sentido, la pobreza de la que hablaba Carrera, será un motivo de representación, dará lugar a figuras, objetos y escenarios: cuartos vacíos, cenas magras, prolongados momentos de soledad, sábanas raídas: la afectividad y lo sensitivo también registran señales desvaídas. Por su parte, Mario Cámara situó este problema en términos de hastío o de Spleen del presente (Sibila). Con sus rituales y ceremonias, los sujetos históricos de la nomadía actual registran tramos baldíos; ahora, las calles y los interiores, cotidianos y domésticos, se manifiestan en estado de saqueo. Los autores citados y otros ajustan cuentas con su tiempo y con su espacio (la realidad), asumiendo la intemperie, el desamparo, como ambiente y soporte de una experiencia: la comunidad (ver Roberto Espósito).

\section{Las campanas de palo y el "desamparo organizado"}

Gran parte de la escritura constituye sujetos que modulan un tono intimista y confidente buscando el antídoto para entenderse con el descentramiento identitario. Aquí, lo pasajero se vuelve perfecto en su fragilidad adecuada al instante, a la efímera coincidencia entre el yo y el mundo; también, el deseo de una morada coexiste con la dinámica de lo accidental ahí donde la destreza del sujeto consiste en elegir con libertad los vínculos, esto es, sin mandatos morales, imperativos u ontológicos (ver Sloterdijk). Sin embargo, pareciera que la masa se ha vuelto solitaria, desgarrada con individuos extraviados en el cuerpo colectivo y a su vez, cercados por los campos de fuerza ejercidos por los medios de comunicación. Pareciera que los individuos de la sociedad actual (que no llamo posmoderna por no haber transitado por una fase industrial desarrollada y estable, en lo que hace a la Argentina), han perdido la capacidad política y sensitiva, de congregarse en persona porque el mundo virtual nos convoca y nos conecta sin necesidad de experimentar a presencia real, corporal. La imagen de un fotolog es suficiente (ver Sloterdijk). Se trata más bien del desplazamiento del concepto de masa y multitud. Si en los puntos de encuentro confluían las fuerzas del tumulto (acá, antes de los $90^{\prime}$ ), hoy se vive en un espacio (social, urbano y virtual) donde el yo es individua- 
lizado, en tanto partícula perteneciente al repertorio multitudinario del orden simbólico. En internet, el yo es parte de esa masa aunque quizá nunca llegue a ver a aquellos con quienes habla. El cuerpo comienza a establecer sus compartimentos, por lo menos, ese es en parte, un sentido de la experiencia contemporánea. De todos modos, su presentación realiza sus íconos, asumiendo el alcance que cobra la gestualidad y las figuraciones en la cultura contemporánea (ver Rancière: un proceso de estetización de lo político, pueden graduar los efectos de la visibilidad, de su impacto). Sujetos y personajes merodean así sobre la contingencia, que paradójicamente es previsible en la inmediatez del instante. Todo es azaroso y sin embargo, de algún modo, se lo espera. Pero esa pobreza hará del desamparo su conjuro, la partición de una sensibilidad que hará de la carencia, motivo de estetización y diseño territorial. Se trata de segmentaciones y asignación de nuevos lugares para rótulos de pertenencia e identidad. Entonces, la calle y el barrio (Villa Celina de Incardona, The Palermo Manifiesto de Schmidt, Monserrat de Link,) el Conurbano de Cucurto, el trabajo humorístico sobre la realidad política y policial de Berazachussets de Avalos Blacha, el San Telmo de Naty Menstrual (en Continuadísimo) con sus máscaras itinerantes sobre el margen de zonas rojas, pensiones baratas, cines porno, dealers, más algunos perfiles clandestinos que aparentan respetabilidad social por privilegios pecuniarios, serán motivos recurrentes a la hora de construir recuerdos, ficciones documentales y simulacros de identidad. Así aparecerá esa doble entrada donde se puede inscribir el yo librado al devenir del azar y el acontecimiento; acontecimiento que supone la transformación travesti (en el caso de Naty) y la distancia (doble) que la escritura ficcionaliza en la repetición desplazada de los recuerdos (Juan Diego Incardona y Daniel Link con Monserrat y con La mafia rusa). Hablar de experiencia, supone tener en cuenta la escritura, con y más allá de los libros; letra transformada, adaptada como trabajo en las condiciones actuales que propician los sistemas de comunicación. También, experiencia supone concebir a la sociedad actual desde una suerte de autocontrol absorbido, ahí donde sus individuos se adaptan inmediatamente a los aparatos de regulación. $\mathrm{O}$ al menos esos mecanismos de fiscalización (institucionales y consuetudianios) son aceptados en la comodidad de las demandas adecuadas a ellos. De alguna manera, los sujetos son permeables y a su vez constituyen conexiones a través de un lenguaje que incorpora en su inmanencia las tendencias que ya se han desplegado en todas direcciones. No es difícil ver a través de los "personajes", una sensibilidad de lo cotidiano, distribuída entre el juego de valores e intereses culturales y su naturalización. En otros términos, los textos nos hablan de una vida diaria envuelta entre la manipulación y un estado que simultaneamente la supera. Por ello, el diálogo que los "nuevos" artistas establecen con la tradición, tiene que ver con esa misma cartografía migrante, trazada (en los textos) a medida que se va creando el mundo que se habita. Sin parámetros fijos ni normas demasiado claras: la intemperie. Desde esta perspectiva, autores como Link, López, Incardona, Cucurto o Fabián Casas (con Ocio), tienden a confluir en un mismo problema (por encima de temas y estilos), esto es plantear el eje por el cual la vida (del individuo y de la comunidad) se integra con los sistemas de producción y 
reproducción, donde el repertorio de tópicos y el discurso social (no hablo del todo empírico) penetra las conciencias y los cuerpos a través de un sentido: el de la imagen del propio yo. En los autores citados lo que se enfatiza y se lleva al extremo no es una "planicie etnográfica" (como si el discurso de la etnografía pudiera reducirse a "lo plano") sino el uso de la autobiografía (en todos ellos), del relato familiar y de la infancia (otra vez La mafia rusa y Villa Celina) al punto de fingir y proyectar la coincidencia del protagonista con la imagen impresa en la tapa, en la contratapa, en la solapa del libro y en su sistema de circulación. Parte de este sistema de producción simbólica y cultural se afirma en la tecnología de la comunicación y en los usos de los blogs, cuya autenticidad reside en la posibilidad de legitimar o devaluar los objetos culturales (la escritura en este caso puntual) en la velocidad de la comunicación. Es allí donde, en cierto modo caducan las nociones de gusto y calidad ( 0 al menos quedan confinadas a la preferencia personal pero no crítica), ahí cuando la vida y la experiencia producen el espacio objetivo que a su vez, les da su forma. El sentido de propiedad (sobre el lenguaje) asume plenamente su función colectiva lo cual se nota en la "estructura" del blog: velocidad, inmediatez, capacidad de intervención, de exhibición y ocultamiento, según sea el uso del nombre propio, como firma verídica o como seudónimo. "En las nuevas tecnologías, lo local ya deja de ser una isla porque de alguna manera, lo total hoy es lo real y lo real implica lo virtual".

Esto abre camino a un problema que se nos presenta hoy como interrogante: la literatura y la política. Política como tópico, como forma, en tanto elaboración y uso de un lenguaje, de motivos que aparecen lejanos, disipados; política como estrategia preformativa en cuanto al modo de leer y tramar el pacto con la tradición y como momento de lidiar con el mercado y las posibilidades aparentemente ilimitadas de un mundo virtual. El espacio de la red ofrece la cesura entre lo infinito y lo pautado. Llegado este punto cabría pensar que el sentido tomado por las formas de las escrituras argentinas contemporáneas, es el sesgo de la intemperie, en su aspecto técnico y temático. Parecería que en las actuales producciones culturales, se modificó el sistema de filtros y asimilaciones. Entre saturada y desprovista, la historia y la política, en tanto instancias de una experiencia colectiva de lo real, aparecen figuradas de manera instantánea, recogidas en fotogramas sólo en parte reconocibles. Pero ante todo, el síntoma político pasa por destrabar o correr los límites de lo publicable, de lo que puede o no ser dicho (aquello que, modernamente, era blanco de las deliberaciones barthesianas respecto al género del diario íntimo). Hoy, la intimidad promueve ese mismo desplazamiento y se convierte en acto político. Desde la estética y el arte contemporáneo, el deseo de inscribir el propio cuerpo en la escena colectiva borra los límites entre lo público y lo privado. Si el secreto y los enigmas de alcoba estuvieron desde siempre en la literatura, hoy se extrema un aspecto que involucra directamente a la tecnología, liquidando los bordes divisorios entre adentro y afuera (del libro, del texto, de la palabra). En este sentido, los nuevos géneros del blog, del Facebook, del Messenger y del chat, ponen de manifiesto la disolución de los segmentos de lo propio y lo ajeno, lo interior y lo externo. También, es discutible hasta que punto 
pueden ser llamados géneros, en tanto técnicas por las cuales emergen lenguajes que coinciden por dependencia y determinación, de su soporte. Pues así como los mensajes de texto en telefonía celular son concisos, abreviados, rápidos hasta alterar las normas ortográficas con el fin de garantizar la eficacia de la comunicación, muchos de los textos que leemos hoy son precisos y faltos de ornamento o de indicios de especificidad artística. Por otro lado, Internet nos habilita para preguntarnos si conecta o separa a los individuos de una comunidad, favoreciendo el acceso a materiales (libros, películas, discos, amigos) en el espacio solitario de los interiores domésticos. La ciudad reserva nuevos espacios a la sensibilidad de los sujetos, allí donde la delgada línea entre interioridad y exterioridad opera de un modo radicalmente lábil. Sin embargo, este desplazamiento asume la condición y la posibilidad de exhibir/se y acceder, construyendo páginas y web sites, blosgs y facebooks, mecanismos que promueven la intercomunicación inmediata dando a conocer incluso aspectos y perfiles de la personalidad; cabe también advertir que las páginas y muros de estos sitios consisten parcialmente en síntesis de gustos y tendencias, moldeando previamente frases slogans a las cuales los usuarios pueden adscribir. Tratándose de facebooks, las afinidades y elecciones son parciales y dependen del grado de aceptabilidad en los sujetos, de la cuantificación que instala con eficacia, expresiones y objetos de deseo.

\section{Específico y heterónomo}

En el presente, los textos, "poéticos", "narrativos", "teórico-críticos" (pensemos en Fantasmas, de Link) dejan a las claras que la autorreferencialidad en tanto caución de autonomía, es un concepto caduco. Porque si es cierto que los productos siguen hablando de sí mismos, lo hacen desde una instancia que no cierra modo de trabajo, materiales, temas y referentes. Consecuentemente, más allá del relato y la figuración, la curva pornográfica (cfr. Ferrer) que hoy marca presencia, atañe al umbral de una forma, reafirmando la simultaneidad entre realidad y ficción, nivelando el artificio y el procedimiento con el objeto a ser representado ((realidad en el sentido de Rancière, como la dimensión figurativa donde el cruce entre lo político y lo estético, lo ideológico y lo social se produce en un borde simultáneo, lo cual supone una suerte de inscripción material). Producción cultural en tanto artefacto migrante, donde la nomadía indica el pasaje de ida y vuelta por el campo digital. En este sentido, utilizo el término de bioficción, noción que señala la horizontalidad entre práctica y resultado, entre la fabricación y la materia, entre el procedimiento y sus mitologías. De allí deviene un proceso cuya lente aumenta su propia escena, volviendo familiar la indistinción entre literatura y ambiente. Si dicho fenómeno puede tener en algunos críticos serias impugnaciones, creo que es cierto algo que Cecilia Pavón sostenía en un programa de entrevistas del prestigioso canal A. Hoy la literatura es su contexto, tiene que ver sus soportes y sus medios; diríamos sin horror ni juicio de valor, que no hay división entre circuitos y el mundo que "retratan", entre la puesta en circulación, la performance y las estrategias de legitimación. Y esto comprende a la praxis estética en su conjunto, la escritura, la plástica visual, la música y la actuación. Damos algunos ejemplos 
multifacéticos con los nombres de Gabriela Bejerman y Dani Umpi. La primera poeta, el segundo narrador autoproclamado heredero de Manuel Puig que llegó con difererentes resultados, al medio televisivo. Mientras, Bejerman es coetánea de Cecilia Pavón, Fernanda Laguna, Karina Maccio, Marina Mariasch, Verónica Viola Fischer, Roberta Ianamico, Romina Freschi y Anahí Mallol. Pero más allá de las instalaciones, galerías, exposiciones, talleres, revistas y editoriales que promueven grupos como Belleza y Felicidad o Zapatos Rojos, algunos desprendimientos (es el caso de la revista Plebella, dirigida por Freschi), otros emprendimientos (como la editorial Siesta, codirigida por Mallol junto a Santiago Llach), Gabriela Bejerman participa con cierta frecuencia como jurado en certámenes de poesía (junto a Emiliano Bustos y Romina Freschi) y ha participado en el megaproyecto cultural de Estación Pringles (organizado por Arturo Carrera y Chiquita Gramajo) con un celebrado Cabaret Literario. Tal evento se realizó junto al dictado de talleres magistrales (Mario Bellatín, Maria Moreno, Ariel Schettini, Daniel Link, etc.) y un biodrama poético a cargo de Vivi Tellas más el apoyo de medios culturales como La Nación y alguna que otra nota aparecida en Clarín. El conocido blog de Link, también contribuye a difundir las actividades. Este es apenas un bosquejo de una estructura que se impone como un circuito de legitimación que también involucra a la Universidad (no solo con programas de estudio, sino también desde revistas cibernéticas surgidas en Puán, entre estudiantes y graduados destacados como escritores, como críticos e investigadores: El interpretador, Planta, NoRetornable, a su vez, enlaces recíprocos). Asimismo, el proyecto cultural radicado en Bahía Blanca propiciado por Gustavo Lopez, se promueve con su revista Vox virtual, catálogo informativo de eventos culturales, muestrario de escrituras. Entonces, la publicidad ingresa en la trama, donde el hacer artístico proyecta a su vez esa insistente e intensa gestualidad de hacerse ver. Cuando nos preguntamos por la supuesta función y operatividad de lo político, deberíamos tener en cuenta qué lógica de inversiones y subsidios, patrocinios vinculados con aparatos gubernamentales $u$ otras entidades y fundaciones, facilitan la necesaria instrumentación de la producción de cultura. Si lo político es un término que se propone como encrucijada, lo popular también. ¿Qué es hoy cultura popular? ¿Intereses y gustos estandarizados? Qué lugar ocupan los biodramas de Tellas en Bahía Blanca, Estación Pringles, los ciclos de los martes en la librería editorial Eterna Cadencia, los talleres impulsados por Belleza y Felicidad, Eloisa Cartonera, con su componente ideologico y social. La presencia del nombre sigue de alguna manera haciendo falta.

\section{Más acá del mundo. Los textos, el pasado y la realidad}

Si es cierto que conceptos filosóficos como hombre y ser anidan en la metafísica occidental (cfr. Carta al humanismo de Heiddeger, Extrañamiento del mundo de Sloterdijk, muestra de cómo se deconstruyen esos conceptos) también es verdad que la trascendencia que conllevan decae para reponer en su lugar al cuerpo y su materialidad, lo que tiene que ver con la réplica que la biotecnología ofrece, esto es la operabilidad y la automanipulación del yo (réplica como copia, impos- 
tación y contestación, nota al pie). Dispositivo y artefacto, naturaleza informada (informatizada) toma terreno respecto respecto del reconocimiento atávico del hombre y sus ancestros). En la cultura contemporanéa, la experiencia transfigura la subjetividad, por cuyas prácticas negocia su constitución y su albedrío. Nerds, estudiantes de letras, adictos a la moda (Pola Olaixarac en Las teorías salvajes), viajeros y observadores de la realidad (Florencia Abbate en Magic resort, sujetos a mitos políticos en el extrañamiento del presente como el peronismo de Incardona en Villa Celina, viejos barrios convertidos en zonas de tránsito y exposición cultural (Esteban Schmidt en The Palermo Manifiesto) los textos de hoy se hacen cargo de las nuevas mitologías urbanas. En todo caso, los sujetos son usuarios de un sistema que pone de manifiesto la vigencia o la rescisión de las normas y modelos a seguir. "Si el mundo nos sorprende con algo, lo miramos por Internet que es más rápido y más limpio. No tenemos ningún compromiso con la tradición del papel. No tenemos ningún compromiso con ninguna tradición. Vinimos a inventar, a dejar una huella. Estamos en el negocio de las variedades de té, estamos en el negocio de la comida étnica, nos caben las religiones, las integramos a nuestra creación". La cita pertenece a The Palermo Manifiesto de Esteban Schmidt, incluído en la antología preparada por Santiago Llach y Juan Diego Incardona, Los días que vivimos en peligro, editada por Emecé, incluyendo relatos de Martín Kohan, Martín Eguía, Sol Prieto y Ana Wajszcuk entre otros. Pero hay una particularidad en el texto de Schmidt y es la falta de puente entre la pertenencia ironicamente resignada a una mayoría y el autorreconocimiento en las minorías absolutas que "molestan cuando hablan de sus costumbres". El narrador forma parte de una historia que la escritura admite en la declamación alfonsinista del preámbulo constitucional, pasa el menemismo y sobrevuela los 2000, con la carga de estafa y frustración que implica sobrevivir en la Argentina, nombrada en el contraste del mito solemne de la "patria" y la mirada cínica de quien no desiste en testimoniar la historia de estafas y frustraciones, de inocentes y fugaces ideales democráticos más efímeros sueños de goce en viajes al exterior, a muy bajo costo. Pero el fraude de la felicidad, se convierte en tópico para los transeúntes de Buenos Aires y donde si se traza una zona de pasaje es entre Caballito y Palermo. La narración se organiza con el ritmo, modos y tiempos verbales de la arenga hecha cuento, de la palabra puesta a prueba en la tribuna de un amplio llamado a "compañeras y compañeros". El destinarlo está marcado pero el sentido del discurso toma el microrumbo de la tribu, que ya es comunidad parcelada. El narrador incluye a Esteban, Estebitan, en una tercera persona cuando se trata del nombre que coincide con el del autor. Por lo general, el sujeto de enunciación habla en primera persona del plural y digo habla porque la urgencia verborrágica tiende a estilizar la oralidad, o al menos plantear una situación comunicativa que establezca algún feedback con el lector (o los oyentes). La precisa actualidad de ciertos giros, ademanes y expresiones buscan el destino de una rabia cuyo antídoto es Un gallo para Esculapio. Desde una ultraminoría cosmopolita y desafectada, en apariencia fría, el narrador compone un tono sentencioso y apodíctico. "Entonces fue que sacándole carga moral, nos desmoralizamos". Ha cierto tono compartido entre 
Schmidt y aquel "verso" de Metal pesado, de Alejandro Rubio "Me recontracago en la chota democracia". Si no se trata de oposición sistemática a un programa político, sí se trata de un síntoma en tanto manifestación de una crisis. Si hay algo en común entre The Palermo manifiesto y Los domingos son para dormir de Sonia Buddassi, es cierta supervivencia en la deriva sobre un mundo que no promete guardar certezas. Porque aunque es cierto que Schmidt afirma una experiencia, no garantiza ningún punto de llegada. En el caso de Buddassi, los personajes también sobreviven a la intemperie de un sistema de códigos que muchas veces se vuelve indescifrable. Y aquí la soledad, la levedad de los recuerdos y los afectos, es el velo indeciso entre la alternancia de campo y ciudad, complementado a veces con monólogos interiores que potencian una experiencia de tiempo y espacio, sostenida en un lenguaje autorreflexivo donde lo diverso es condición para lo imprevisto.

Dentro de una estética realista que exige descripciones objetivas basadas sobre documentos fílmicos (en lo que hace a la franja de Gaza), Magic resort de Florencia Abbate, propone una visión de paradigmas contrapuestos, entre un Occidente extremadamente secularizado y un Oriente que revela nuevos modos de insurgencia: la religión. A partir de dos historias cruzadas, se nos muestra, por un lado, la hegemonía del consumismo y del éxito, por otro, el momento histórico donde el concepto de civilización entra en crisis, cuyo factor emergente es la violencia que estigmatiza el mundo musulmán. Por lo tanto, en la narración, que elige condensar registros y voces, se enfatiza la experiencia de un momento histórico, donde la mirada de una sociedad sumida en exigencias económicas y en trastornos de bipolaridad, evidencian los conflictos propios de hallar lo local en la era de la globalización. Sin embargo, declaraciones de la autora acerca de la falta de "modelos agobiantes" en las producciones de la cultura actual se ven, en cierto modo, contradichas con el grado de problematización ideológica, étnica y social que logra el texto. Acaso el factor político no ha dejado de existir sino más bien se ha desplazado hacia otros enfoques; así, la oposición Arlt/Borges que según Abbate funcionaba en contextos politizados, podríamos pensarla hoy como nombres que drenaron en nuevos lectores, necesidades y deseos, habiendo borrado aquel taxativo signo de antinomia.

Cuando Sarlo dice que en internet no hay incertidumbre, se refiere a una suerte de feria enciclopédica que asegura la posesión instantánea de datos y referencias. Si nos puede resultar paradójica la certeza como atributo del mundo virtual, la lectura de Sarlo refrenda irónicamente la erudición en los tiempos de Google, con un discurso mucho más cuidado que sus devastadores ataques dirigidos contra Paula Vasarvski, Romina Paula (cuyos textos son metonimias del mundo sito en Puán y Pedro Goyena), Cucurto y Alejandro Lopez. Digamos de paso que el reparo de Sarlo hacia nuevos nombres, con valoración positiva o juicio negativo, no deja de funcionar para los aludidos, como pase ansiado a la "fama" rápida y segura. Así, en la nota que le dedica en Perfil a Pola Olaixarac, vuelve a instalar una involuntaria cadena de favores. Parece ser que Las teorías salvajes, "refleja" todo lo aprendido en la Facultad de Filosofía y Letras, capital simbólico que, desde una 
mirada deliberadamente inocente y cierta resonancia del género picaresco, es arrojado por su autora al exitoso e incipiente sello de Eterna Cadencia. Ahora bien, si por un lado la autora combina lecturas y citas, inscribiéndose en la tradición novelística de aprendizaje e iniciación, a su vez sintoniza la frecuencia con su propia época para esparcir con ritmo y eficacia el repertorio de una etnografía urbana de minorías culturales. Aquí, la ciudad, lejos de ser el fondo estático donde se estampan estereotipos, es el ámbito provocador y cómplice activo cuyos comercios, plazas, calles, centros culturales, bares y La Facultad de Filosofía y Letras, promueven estilos de vida, actitudes y fisonomías. El ritual intimista de la narradora de leer junto a su gata, describir gente cool y fashion se conjuga con la tendencia de incursionar viendo de cerca en la fealdad y la escatología. La puesta sobre un mismo nivel con el recurso de la sinestesia en sus amplias posibilidadades logra eficacia, a excepción quizás de un punto que a mi modo de ver, es crucial para leer los textos de las nuevas generaciones: el factor ideológico y político. Porque aquí ingresan recuerdos de infancia que retratan a padres y adultos militantes y así, la narradora recrea al intelectual de izquierda desde una perspectiva satírica, encontrando divertido deslizarse por las páginas de un diario íntimo. Ahora bien. Sarlo aquí sí critica duramente el procedimiento de una parodia frustrada porque según su punto de vista, debe implicar la exacta idea del texto que se tiene enfrente, cosa que acá no ocurre. Llegada esta cuestión, creo que debemos detenernos en algunos problemas y preguntarnos cómo funciona la formación de la autora. A) en término generales, la memoria: la histórica, la cultural, la política. B) en términos genérico discursivos, plantearnos el uso de la parodia y de la sátira y en que consiste su distinción. Quizá parodia se refiera al intertexto, al género o al discurso que funciona como su objeto de representación (de volver a traerlo a un nuevo contexto desde otra versión). Quizá la sátira consista en un juego más gestual, más histriónico, implicando menos el lenguaje en sí y más en primer plano aspectos preformativos, acciones revestidas de señas y lenguajes determinados. De algún modo la sátira, más allá de iniciarse con la incorporación del mundo bajo que mueve a risa, funcione mejor en un contexto coyuntural y presente. Lo cual me lleva a pensar, más allá de que el procedimiento esté bien realizado o no, en que Olaixarac es una autora consonante en gran medida con sus últimos congéneres. Lo admitan o no, ellos llegan al punto de donde Aira partió, como ficción de un programa estético, basado en una alta y sofisticada formación intelectual. Aquello que Aira hizo sonar como foco de su posición polémica era la trivialidad y la incorrección, cuestiones que Aira manejó a conciencia en su escritura tensada sobre la tradición más arcaica y la vanguardia histórica más experimental con los ready mades de Duchamp. Allí había una idea de que la novela debía narrar historias motivadas en la acción cuyas posibilidades eran tantas, que excedían el mandato vetusto de la profundidad. Todo rueda en la superficie del lenguaje y como sabemos por Deleuze y sobre todo por Valéry, "lo más profundo es la piel". Pero ahora sucede algo que tiene más que ver con lo relativo de la abstracción; la escritura que traza perfiles coincidentes con una experiencia probable, exige un grado de generalización que pierde contacto con lo concreto y la singularidad. Además, los 
guiños y señales que nos remiten a la dirección porteña (otra vez) de Puán y Pedro Goyena (Facultad de Filosofía y Letras, Universidad de Buenos Aires), solicitan una respuesta rápida, la competencia de una identificación sin titubeos. Como si algunos de los más recientes autores formularan sus poéticas desde el sentido literal de superficie, la banalidad del entretenimiento o de la reflexión vaciada de memoria histórica. Como si se tratara de una escritura cuyo mayor riesgo es la ansiedad, marcada por la saturación donde todo lo aprendido en la facultad o en los talleres, es volcado en un tiempo que termina con la espera, con el impasse de donde surgen las marcas que identifican una poética y un nombre propio.

\section{Bibliografía:}

ABBATE, Florencia. Magic Resort. Buenos Aires: Emecé, 2007.

AGAMBEN, Giorgio. Infancia e historia. Buenos Aires: Adriana Hidalgo editora, 2001.

AVALOS BLACHA, Leandro. Berazachussetts. Buenos Aires: Entropía, 2007 (Premio Indio Rico, Estación Pringles).

BIZZIO, Sergio. Infierno Albino. Buenos Aires: Sudamericana, 1992.

. Rabia. Buenos Aires: Interzona Editora Latinoamericana, 2005.

BUDASSI, Sonia, Los domingos son para dormir, Buenos Aires: Entropía, 2008.

BUSTOS, Emiliano. Cheetah. Buenos Aires: El suri porfiado, 2007.

CAMARA, Mario. "El spleen del presente". Revista digital Sibila, número 13, 2007, San Pablo.

CARRERA, Arturo. Monstruos. Buenos Aires: Fondo de Cultura Económica, 2001.

CHEJFEC, Sergio. Lenta biografía. Buenos Aires: Punto Sur, 1990.

. El aire. Buenos Aires: Alfaguara, 1992.

. Los planetas. Buenos Aires: Alfaguara,1999.

. Baroni. Buenos Aires: Alfaguara, 2007.

. Mis dos mundos. Buenos Aires: Alfaguara, 2008.

ESPÓSITO, Roberto. Immunitas. Protección y negación de la vida. Buenos Aires: Amorrutu, 2005.

. Communitas. Origen y destino de la comunidad. Buenos Aires, Amorrutu,

2003.

FERRER, Cristian. "La curva pornográfica. El sufrimiento sin sentido y la tecnología". Revista Artefacto. Pensamiento sobre la técnica, número 5, 2004, Buenos Aires.

GAMBAROTTA, Martín. Punctum. Buenos Aires: Tierra Firme, 1996. . Seudo. Bahía Blanca: Vox, 2000.

HARDT, Michael y NEGRI, Antonio. Imperio. Buenos Aires: Paidós, 2002.

INCARDONA, Juan. Villa Celina. Buenos Aires: Grupo Editorial Norma, 2008.

. El campito. Buenos Aires: Sudamericana/Mondadori, 2009.

LINK, Daniel. Monserrat. Buenos Aires: Mansalva, 2006.

. La mafia rusa. Buenos Aires: Emecé, 2008. 
Fantasmas. Buenos Aires: Eterna Cadencia, 2009.

MENSTRUAL, Naty. Continuadísimo. Buenos Aires: Eterna Cadencia, 2008.

NANCY, Jean-Luc. 58 Indicios sobre el cuerpo. Extensión del alma. Buenos Aires:

La Cebra, 2007.

OLOIXARAC, Pola. Las Teorías salvajes. Buenos Aires: Eterna Cadencia, 2009.

PAULS, Alan. El pudor del pornógrafo. Buenos Aires: Sudamericana, 1984.

. Wasabi. Buenos Aires: Alfaguara, 1994.

. El pasado. Barcelona: Anagrama, 2003.

RAIMONDI, Sergio. Poesía civil. Bahía Blanca: Vox, 2001.

RANCIERE, Jacques. La partición de lo sensible. Salamanca: Centro de Arte de Salamanca, 2002.

. En los bordes de lo político. Buenos Aires: La Cebra, 2007.

RODRIGUEZ, Martín. Agua negra. Buenos Aires: Siesta, 1998.

RUBIO, Alejandro. Metal pesado. Buenos Aires: Siesta, 1999.

SLOTERDIJK, Peter. Extrañamiento del mundo. Valencia: Pre-textos, 2001.

El desprecio de las masas. Ensayo sobre las luchas culturales de la sociedad moderna. Valencia: Pre-textos, 2002.

Title:

Cultural productions in contemporary Argentina. Experience and sensibility

\section{Abstract:}

The present work intends to think the cultural and artistic productions in contemporary Argentina, taking into account the writers and critics Alan Pauls, Sergio Chejfec and Daniel Link. The category of symptom (Freud, Sloterdijk) shall function here as a key to analyze the meaning of experience, of history, of the real, the identitary strategies, the urban and territorial space, the current social dynamics and the place that the very cultural production demands in relation to its own conditions of possibility, and its links with the new circuits of legitimation.

\section{Keywords:}

Cultural production; experience; image; intimacy; community 